\title{
HOW MUCH IS APHID POPULATION DYNAMICS AFFECTED BY THEIR NATURAL ENEMIES? AN EMPIRICAL EXAMPLE FROM GREECE
}

\author{
ZUZANA ŠTÍPKOVÁ1,2,* and PAVEL KINDLMANN ${ }^{1,2}$ \\ ${ }^{1}$ Global Change Research Institute, Bělidla 986/4a, 60300 Brno, Czech Republic \\ ${ }^{2}$ Institute for Environmental Studies, Faculty of Science, Charles University, Benátská 2, 12801 Prague, Czech Republic \\ * Corresponding author: zaza.zuza@seznam.cz
}

\section{ABSTRACT}

By monitoring of 50 aphid colonies in 2017 and another 50 colonies in 2018 twice a week, we looked at how the aphid dynamics was affected by their natural enemies. This will help us to see, how much the presence of natural enemies shortens the duration of an aphid colony, which may be one of the causes, why Harmonia axyridis is not very successful in the Mediterranean: the aphid colony may exist for a period of time too short in the Mediterranean conditions to enable successful development of H. axyridis.

Keywords: Aphids; population dynamics; Harmonia axyridis; colony

\section{Introduction}

Invasive alien species belong to the major drivers of biodiversity loss (Hilton-Taylor 2000). The harlequin ladybird (Harmonia axyridis) is an invasive alien species, which has probably escaped from the glasshouses in the Netherlands, country of its initial wild occurrence in Europe, and is now quickly spreading all across Europe (Brown et al. 2011; Roy et al. 2012). During the last decades, its distribution was reported from some countries very far from the place of its initial spread: from Ukraine, Turkey or Georgia (Roy et al. 2016). It is therefore interesting to see, what is the distribution and dynamics of aphidophagous guilds and aphids in these "distant" countries.

From the spreading of $H$. axyridis some practical and interesting question have arisen: 1) Will Harmonia axyridis suppress the abundance of native species of lady- birds? 2) What will be the results of $H$. axyridis arrival for aphid biocontrol?

Here we present results of a pilot study performed in one site in Greece as an example of a destination at the margin of $H$. axyridis distribution, where this species is still absent or is present only in small numbers. We looked at the structure and dynamics of aphidophagous guilds and aphids here, with a special focus on the dynamics and distribution of $H$. axyridis. We were not able, however, to measure any functional responses sensu Pervez et al. (2018) or Pervez and Yadav (2018), as the data were too scarce for this.

\section{Methods}

The data was collected in north-eastern Greece around Néa Péramos village, which is situated on the coast (Fig. 1).

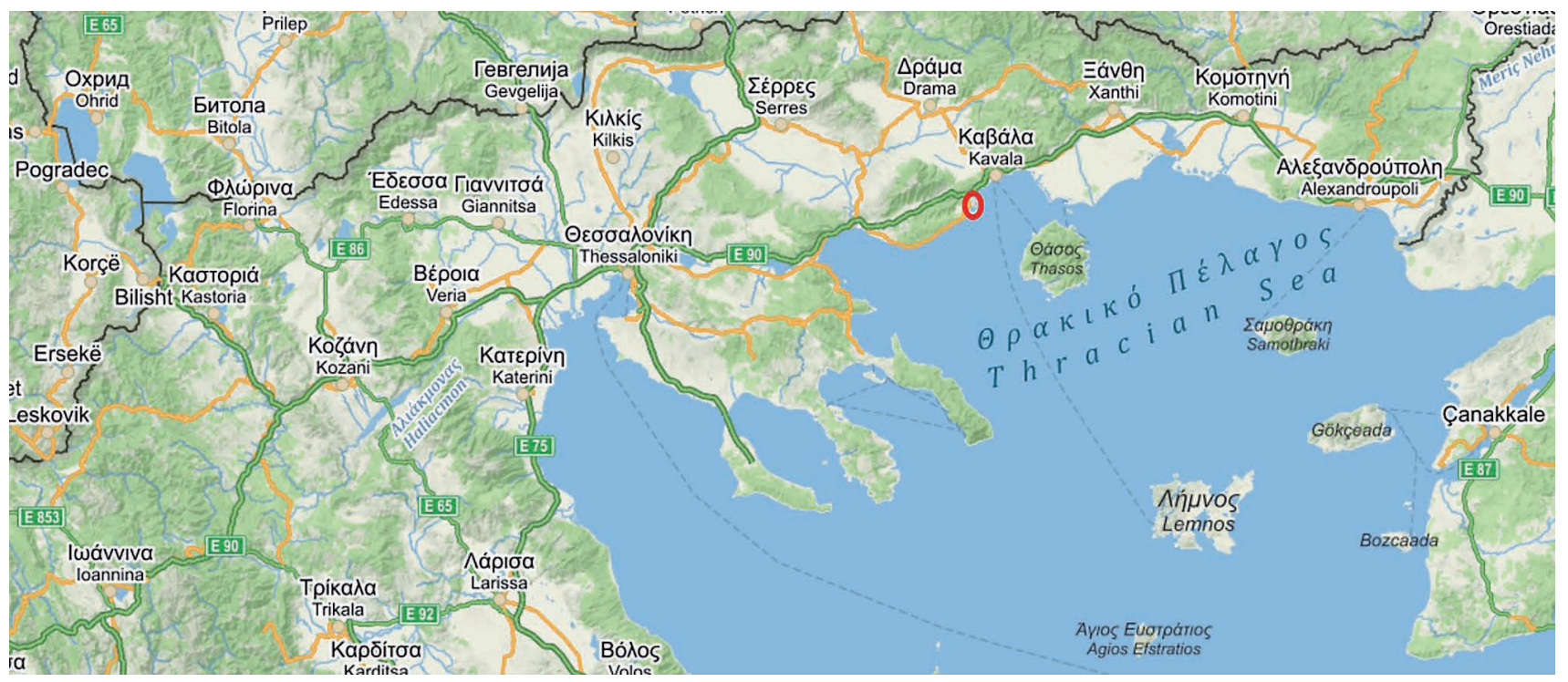

Fig. 1 Location of the study sites. The red ring shows where Néa Péramos is situated. 
We spent there a total of five months during 2017 and 2018, each year from April to mid of June, when aphid colonies occurred there.

In the field, we looked for aphid colonies on different plants around the village and when we found a suitable colony, we marked it by GPS and attached a colour label to the plant. In every aphid colony, we monitored the numbers of aphids and ladybirds (larvae, pupae and adults), other aphid enemies and also any kinds of changes within the colony. We excluded trees from our research in 2018, because of possible sampling error and because in 2017 we observed that aphids stayed on trees during the whole season, which made considerations of the colony duration irrelevant.

We visited marked colonies every 3 days and counted the aphids and their enemies on the whole plant. For making it a bit easier, especially in the case of trees, we tried to choose only smaller individuals of plants - smaller trees, single standing raspberry sprouts and so on. In total, we monitored 50 aphid colonies in 2017 and another 50 colonies in 2018. The monitoring was performed twice a week during the whole season.

To describe aphid population dynamics, we used the population dynamics models described by Kindlmann et
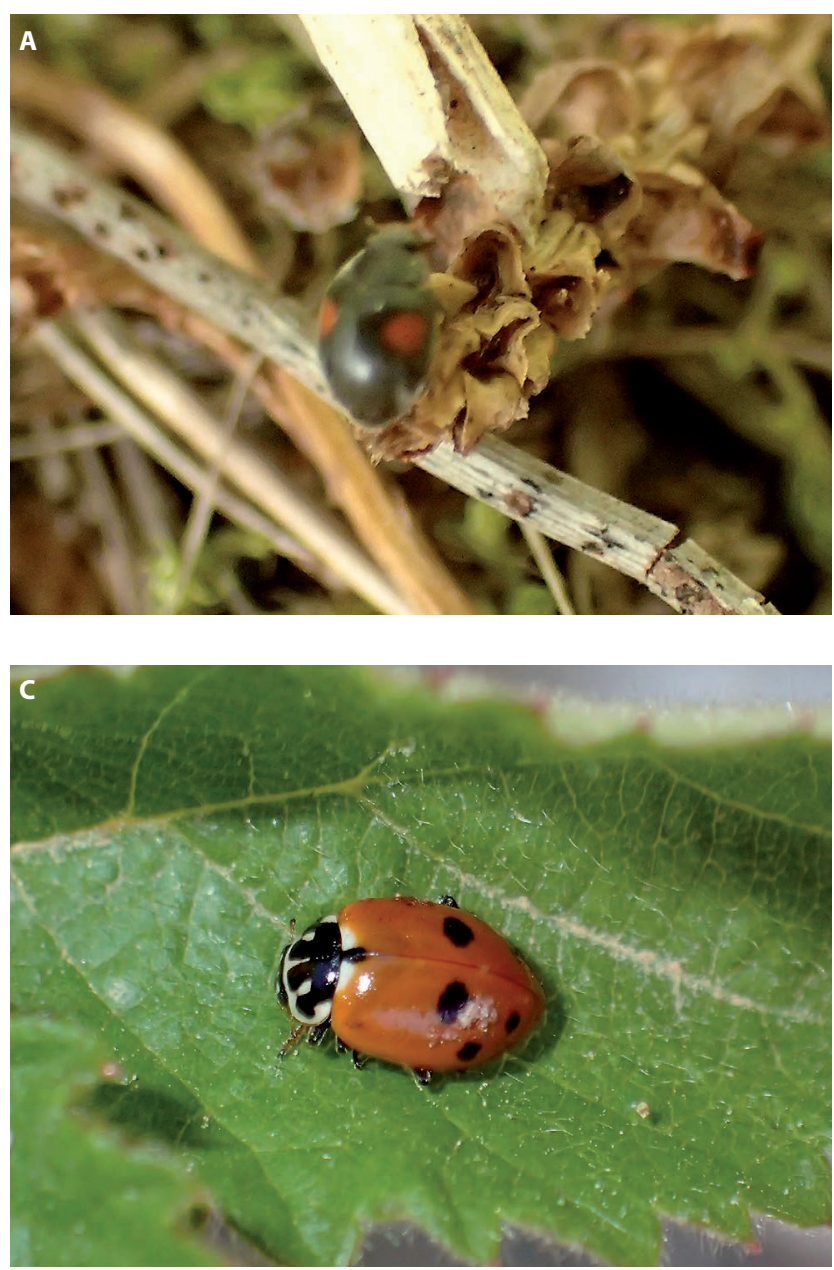

al. (2004) and Kindlmann and Dixon (1999). The rate of change of aphid abundance is described as exponential growth of the aphid population and density dependent factor, where, instead of carrying capacity used in logistic equation, we used aphid cumulative density - the cumulative number of aphids from the beginning of colony existence:

$$
x^{\prime}(t)=r x(t)\left[1-\alpha \int_{0}^{t} x(\tau) d \tau\right]
$$

Here $x(t)$ means number of aphids at time $t, x^{\prime}(t)$ means change of the number of aphids per unit time at time $t$, $r$ means instantaneous growth rate of the aphid population (in exponential growth), a means intensity of regulation (scaling constant, inversely proportional to carrying capacity of the plant) and $\int_{0}^{t} x(\tau) d \tau$ means cumulative number of aphids from the beginning of the colony existence.

Sometimes we had to estimate the exact arrival date of aphids in case that there were already more aphids when we first observed the colony. Then the dynamics was simulated backwards by an exponential. For the estimation of parameters, we used Euler method (minimum residual sum of squares) and module Solver in Excel to get parameters $a$ and $r$.
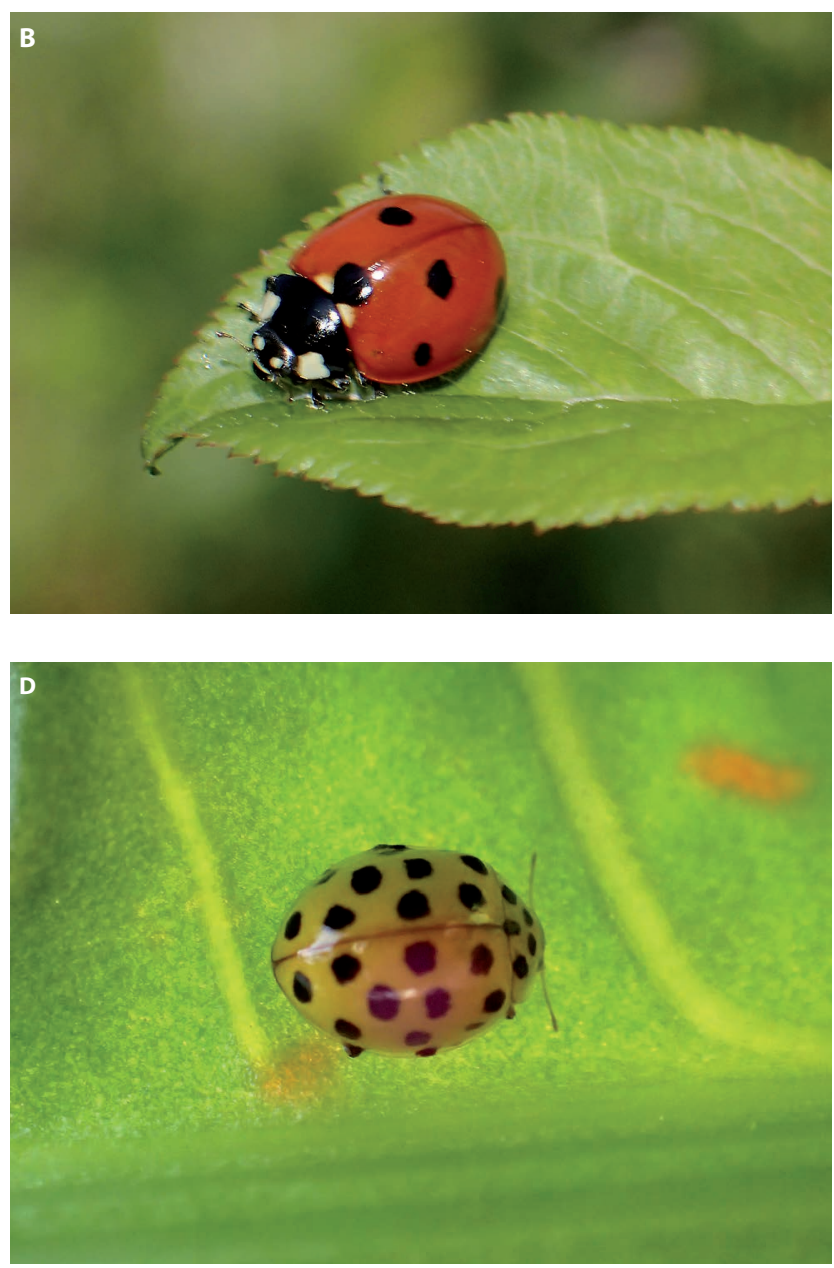

Fig. 2 Ladybird species observed during 2017 and 2018. (a) Adalia sp., (b) Coccinella septempunctata, (c) Hippodamia variegata, (d) Thea 22-punctata. For Harmonia axyridis see Fig. 3. 


\section{Results and Discussion}

We observed frequent diversions in aphid population dynamics from the predictions of model (1): both natural and human-caused ones. Natural diversions were mainly caused by aphids being fed by their enemies (ladybirds in most cases). Diversions due to human influence (often causing destruction of the whole colony) were a consequence of mowing or animal (mainly goat) grazing. We were not able to explain the reasons for diversions in some colonies. Sometimes the reason for diversion might have been due to sampling error, small numbers of aphid individuals or even unknown events.

Vast majority of aphid natural enemies consisted of ladybird larvae or adults, followed by hoverfly larvae and parasitoid wasps from the subfamily Aphidiinae. During our observations, we determined the following ladybird species visiting aphid colonies: Adalia sp., Coccinella septempunctata, Harmonia axyridis (conspicua, spectabilis and succinea forms), Hippodamia variegata and Thea 22-punctata (Figs. 2 and 3).

When trees were sampled in 2017 (Fig. 4), ladybirds (both larvae and adults) were dominated by $H$. axyridis (larvae $86.4 \%$; adults $70.6 \%$ ), followed by some individu- als of C. septempunctata (larvae 13.6\%; adults 27.6\%). In 2018 (Fig. 5), however, when we excluded trees from the sampling, the aphidophagous guilds were dominated by C. septempunctata (larvae $93.8 \%$; adults $64.7 \%$ ) followed by some individuals of Hippodamia variegata (23.5\%). We did not observe any adults of Harmonia axyridis in 2018.

In 2017, $H$. axyridis larvae were mainly present on tree species (like apple, peach and Prunus trees) while C. septempunctata larvae were present also on herbaceous plants. Regarding adults, the pattern was almost the same in the case of $H$. axyridis but we found C. septempunctata adults on trees, as well as on herbaceous plants at a higher rate (Fig. 6).

In 2018, the highest abundance of ladybird larvae and adults was observed on Rumex sp. and partly also on Sonchus sp. (mainly C. septempunctata); we also found some adults of Hippodamia variegata, Thea 22-punctata and Adalia sp. When only herbaceous plants in both years are considered, ladybirds were present mainly on Rumex and partly also on Sonchus (Fig. 7).

We also looked at how much the presence of natural enemies shortens the duration of an aphid colony, using eq. (1). According to the theory we tested, this may be
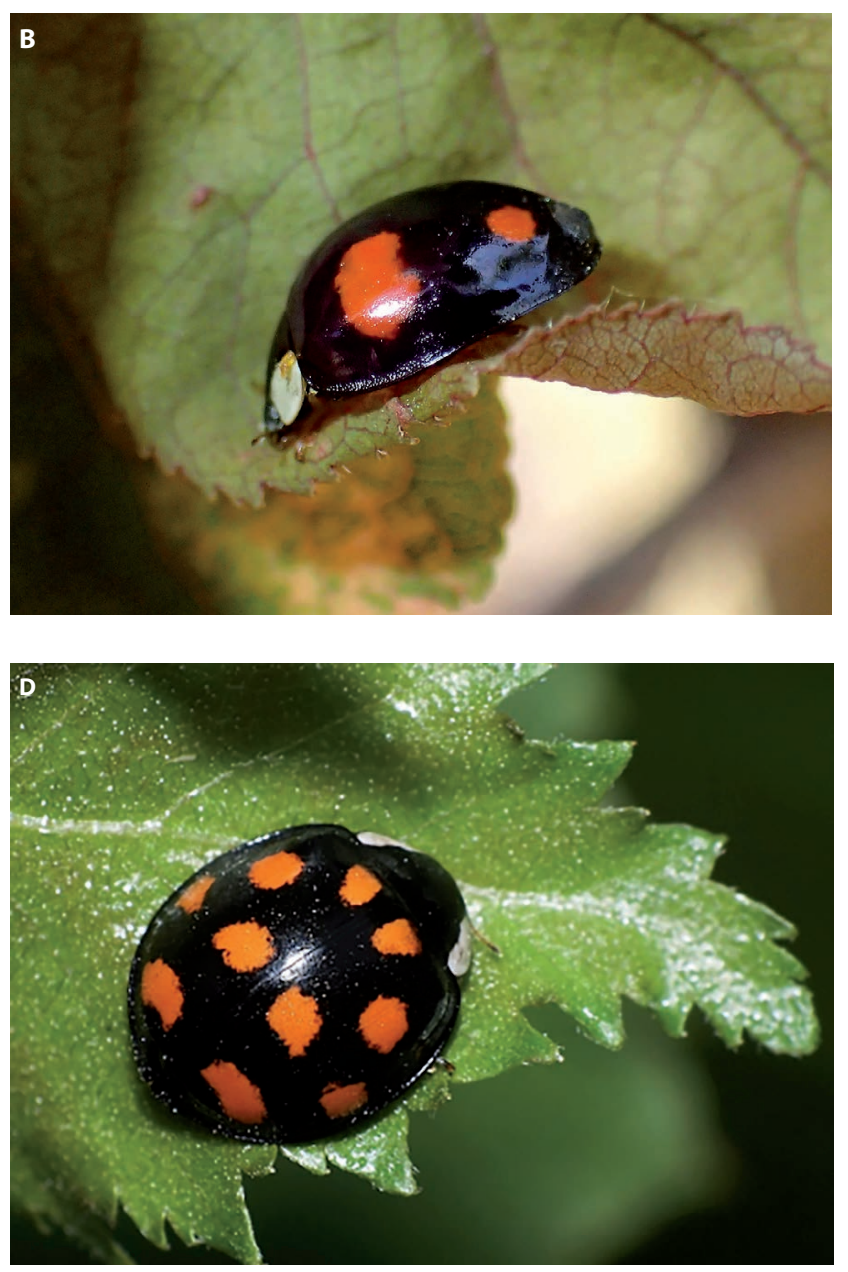

Fig. 3 Forms of Harmonia axyridis observed: (a) f. conspicua, (b) f. spectabilis, (c) f. succinea, (d) f. axyridis (not observed during this study). 
A) Ladybird larvae (\%)

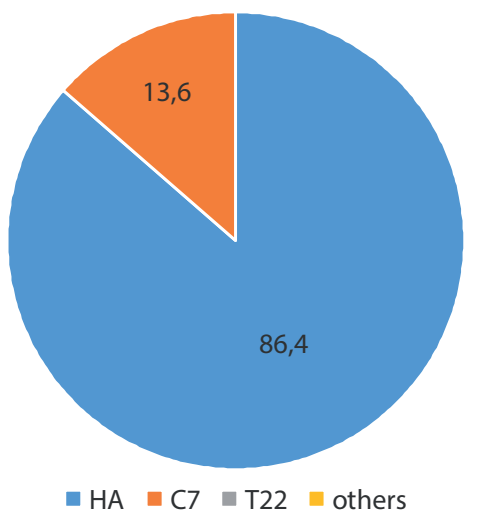

B) Ladybird adults (\%)

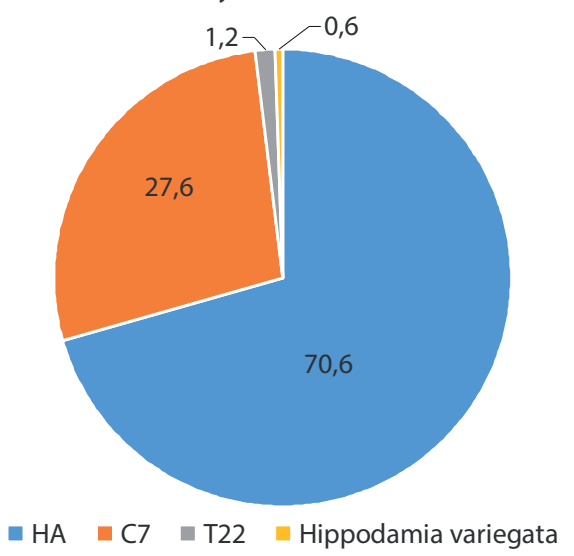

Fig. 4 Percentage representation of particular ladybird species in 2017, when trees were sampled: A) larvae, B) adults.

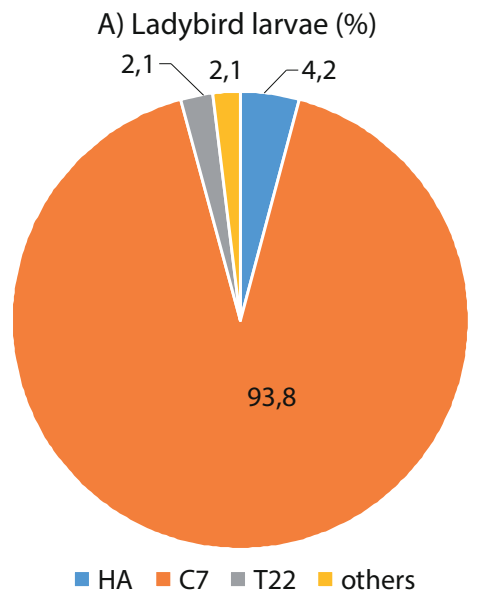

B) Ladybird adults (\%)

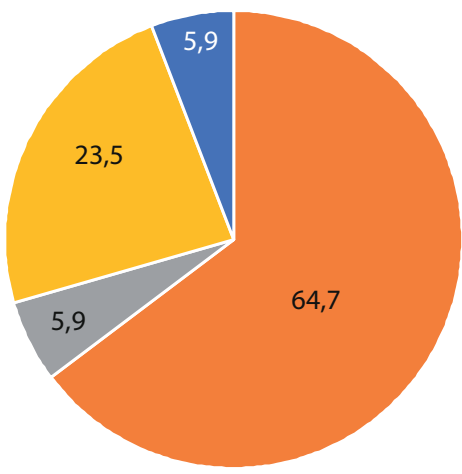

$\square$ HA $\square$ C7 $\square$ T22 $\square$ Hippodamia variegata $\square$ Adalia sp.

Fig. 5 Percentage representation of particular ladybird species in 2018, when trees were excluded from the sampling: A) larvae, B) adults.

A) Ladybird larvae on plants

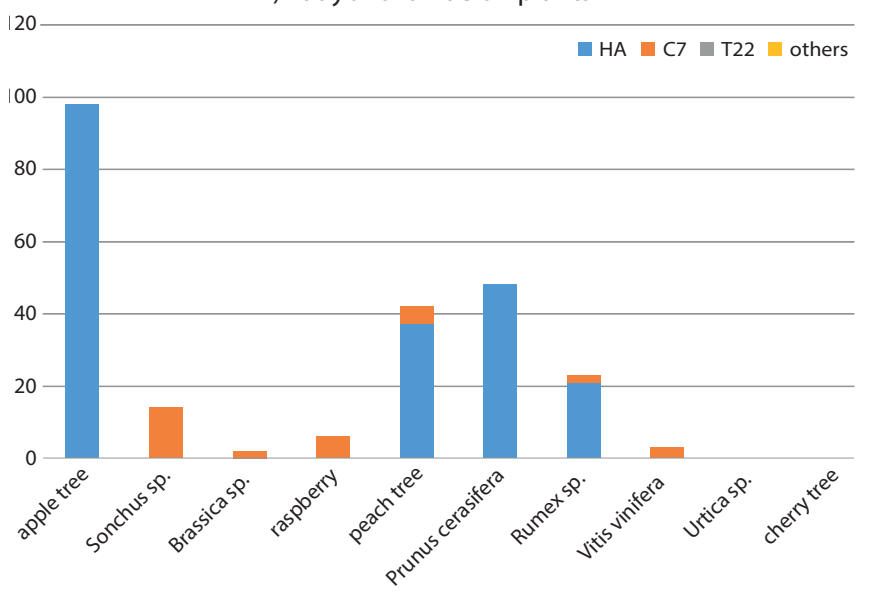

Fig. 6 Plants where ladybirds were observed in 2017: A) larvae, B) adults.

one of the reasons, why Harmonia axyridis is not very successful in the Mediterranean: the aphid colony may exist for a period of time too short in the Mediterranean conditions to enable successful development of $H$. axyridis. The results of this analysis are still under preparation, however.
B) Ladybird adults on plants

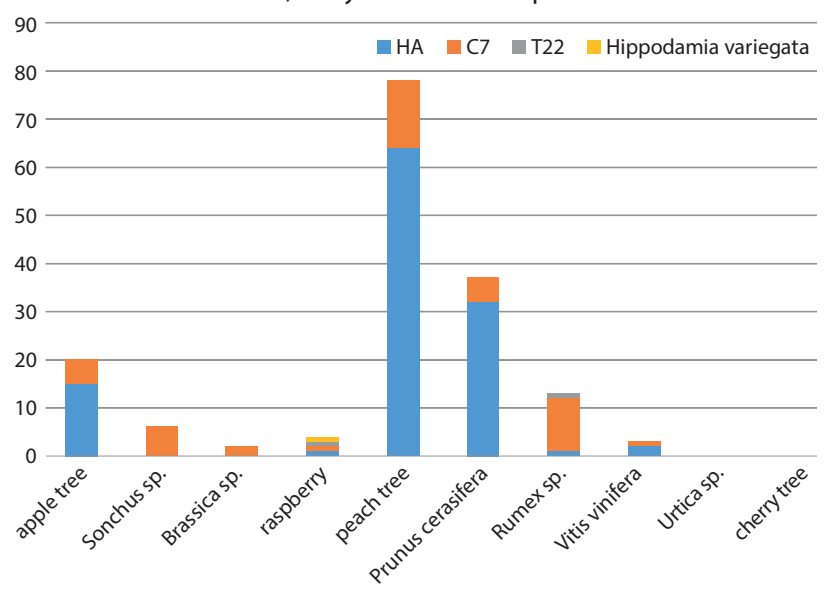

\section{Conclusions}

When trees were not sampled, majority of ladybird adults and larvae was of Harmonia axyridis species, but on the other hand, when trees were excluded from the sampling, the dominating species was Coccinella septem- 


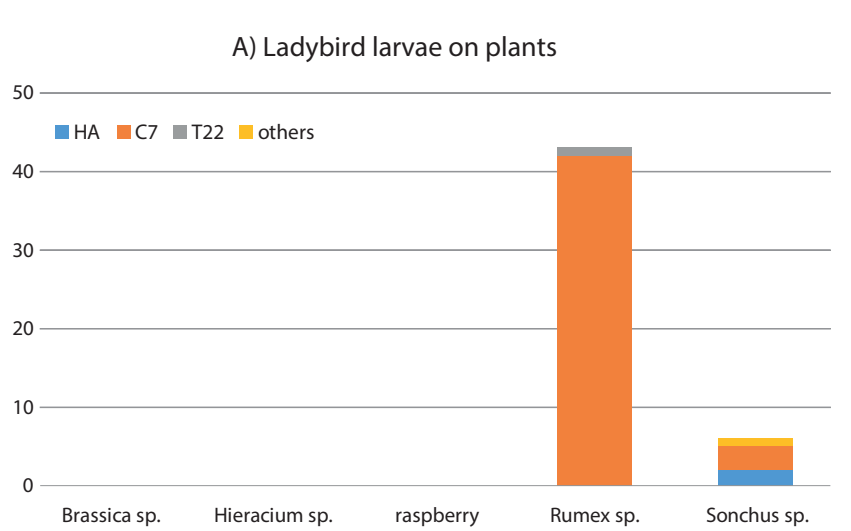

Fig. 7 Plants where ladybirds were observed in 2018: A) larvae, B) adults.

punctata. It may imply that in the Mediterranean climate, $H$. axyridis has a limited time to reproduce and create a new generation.

\section{Acknowledgements}

This project was supported by the grant no. 17-06763S of the Grant Agency of the Czech Republic. We would like to thank to all of our collaborators that helped us in the field and with determination of insects, mainly to A. Honěk, S. Tsiftsis, M. Pultr and M. Habinová. We also thank to the South Bohemian Branch of the Land Office in Ceske Budejovice for cooperation in data collection.

\section{REFERENCES}

Brown PMJ, Frost R, Doberski J, Sparks T, Harrington R, Roy HE (2011) Decline in native ladybirds in response to the arrival of Harmonia axyridis: Early evidence from England. Ecol Entomol 36: 231-240.

Hilton-Taylor C (2000) 2000 IUCN red list of threatened species. IUCN.

Kindlmann P, Arditi R, Dixon AFG (2004) A simple aphid population model. In: Simon JC, Dedryver C-A, Rispe C, Hullé M (eds.) Aphids in a new millenium, INRA, Paris, France, pp. 325-330.
B) Ladybird adults on plants

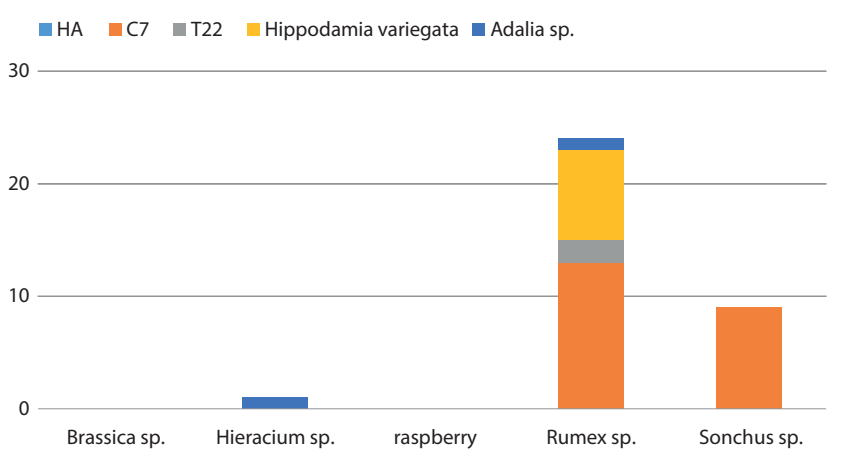

Kindlmann P, Dixon AFG (1999) Strategies of aphidophagous predators: lessons for modelling insect predator-prey dynamics. J Appl Entomol 123: 397-399.

Pervez, A, Singh PP, Bozdoğan H (2018) Ecological perspective of the diversity of functional responses. Eur J Environ Sci 8: 97-101, https://doi.org/10.14712/23361964.2018.13.

Pervez, A., Yadav, M.: Foraging behaviour of predaceous ladybird beetles: a review. Eur J Environ Sci 8: 102-108, https://doi .org/10.14712/23361964.2018.14.

Roy HE, Adriaens T, Isaac NJB, Kenis M, Onkelinx T, Martin GS, Brown PMJ, Hautier L, Poland R, Roy DB, Comont R, Eschen R, Frost R, Zindel R, Van Vlaenderen J, Nedved O, Ravn HP, Gregoire JC, de Biseau JC, Maes D (2012) Invasive alien predator causes rapid declines of native European ladybirds. Divers Distrib 18: 717-725.

Roy HE, Brown PMJ, Adriaens T, Berkvens N, Borges I, Clusella-Trullas S, Comont RF, De Clercq P, Eschen R, Estoup A, Evans EW, Facon B, Gardiner MM, Gil A, Grezz AA, Guillemaud T, Haelewaters D, Herz A, Honek A, Howe AG, Hui C, Hutchison WD, Kenis M, Koch RL, Kulfan J, Handley LL, Lombaert E, Loomans A, Losey J, Lukashuk AO, Maes D, Magro A, Murray KM, San Martin G, Martinkova Z, Minnaar IA, Nedved O, Orlova-Bienkowskaja MJ, Osawa N, Rabitsch W, Ravn HP, Rondoni G, Rorke SL, Ryndevich SK, Saethre MG, Sloggett TT, Soares AO, Stals R, Tinsley MC, Vandereycken A, van Wielink P, Viglasova S, Zach P, Zakharov IA, Zaviezo T, Zhao ZH (2016) The harlequin ladybird, Harmonia axyridis: global perspectives on invasion history and ecology. Biol Invasions 18: 997-1044. 